\title{
Recordando a Patricio Núñez
}

\author{
Branko Marinov Martinic ${ }^{1}$
}

Conocía Patricioen el verano de 1967 con ocasión de trabajos de prospección en la desembocadura del río Loa, del Programa de Arqueología y Museos, Universidad de Chile Antofagasta, dirigido por Lautaro Núñez. Por entonces yo cursaba el tercer año de Pedagogía en Artes Plásticas y fui incorporado como dibujante y ayudante del proyecto Museo Arqueológico de Antofagasta. Desde entonces mantuvimos una cercana amistad que hizo parte de nuestro trabajo universitario y se extendió a las respectivas familias, siendo vecinos en un conjunto de departamentos. Compartimos tiempos de bonanza y también de angustias y frustración, particularmente durante la dictadura militar que nos obligó al esfuerzo adicional de subsistir en el clima de "universidad vigilada". Un ejercicio de creatividad y destreza semántica en que Patricio era muy bueno, especialmente maquillando sus escritos desde el materialismo histórico, que las autoridades de turno eran incapaces de descifrar. Paradojalmente, no fue eso lo que le acarreó problemas, sino una picardía que cometió cuando el Rector Delegado Julio Tapia (FACH) visitó nuestro Museo. Justo yo me enfermé y a Pato le tocó recibirlo, muy a su estilo, calzando chalas "condorito", el pantalón afirmado con cáñamo y en mangas de camisa... Le costó una exoneración por desacato a la autoridad, que lo tuvo alejado varios meses, pero felizmente logró ser reincorporado.

El Pato era así. Impredecible de reacciones, desordenado, "horrendoadministrador" (como se confiesa Neruda), alegre, simpático, gran conversador ignorante de su tartamudez, ingenioso, amigo leal, afectuoso, consecuente con sus ideas a todo trance, indiferente de modas, títulos y protocolos. Pero también estudioso, trabajador apasionado y disciplinado en sus investigaciones, navegante de libros (de los viejos y de los nuevos), solidario como compañero en el quehacer académico. Un humanista. Lo movía un tremendo compromiso social que trasunta sus escritos como científico y en la proyección de su trabajo en la universidad, desarrollando las funciones de investigación, docencia y extensión con una entrega en que se revelaba su formación original: Profesor de Historia y Geografía del Instituto Pedagógico de la Universidad de Chile.

Es en esa dimensión que quiero insistir, relevando su calidad de educador, extensionista y divulgador científico, pues otros sabrán mejor que yo destacar sus valiosos aportes en ámbitos como la arqueología, la antropología, la historia, el arte y la cultura.

El Museo Arqueológico de la Universidad de Chile Sede Antofagasta fue inaugurado en noviembre de 1973, con la muestra "Evolución de las Culturas Prehispánicas del Norte de Chile". Por lo reducido del recinto, recurrimos a exposiciones temáticas temporales que denominamos "Unidades de Exhibición", con diversos aspectos del desarrollo cultural prehispánico del norte. Por cierto, el primer guión museográfico estuvo a cargo de Lautaro Núñez, arqueólogo jefe del entonces Grupo de Arqueología y Museos, con la participación del equipo. Los contenidos daban lugar al catálogo y un tríptico, de distribución masiva entre los estudiantes. Quedó así definida una suerte de "modelo" para cumplir con la función museográfica de la unidad académica. En mayo de 1974 Lautaro fue exonerado y a contar de la siguiente exposición, Patricio fue el responsable de producir el guión y sus publicaciones: Desarrollo de los Pueblos Pescadores-Cazadores Prehispánicos del Norte de Chile (1974), Textilería y Cerámica Prehistórica del Norte de Chile (1975), Visión de la Prehistoria de Chile (1976), 12.000 años de Historia del Norte Grande (1976).

En 1985 se crea el Instituto de Investigaciones Antropológicas y en 1991, en circunstancias confusas, rectoría cierra el Museo y su contenido es trasladado a bodegas del Campus Coloso, donde nunca volvió a ser habilitado por desinterés de las autoridades. Esto lo menciono, porque cobra importancia la decisión de Patricio y el equipo de continuar con las exposiciones museográficas. En 1995 se inaugura un nuevo ciclo de exposiciones, que se presentaron en el Centro de Extensión de la Universidad de Antofagasta y luego recorrieron por la región. Estas exposiciones itinerantes

\footnotetext{
${ }^{1}$ Ex académico de la Universidad de Chile, sede Antofagasta y de la Universidad de Antofagasta, Antofagasta, Chile. bmarinovm@gmail.com
} 
fueron el producto de Proyectos de Extensión de Patricio y siempre consideraron un tríptico y un folleto/guía, que a veces se editaba en formato de libro, de su autoría: Diseños en la textilería del norte de Chile (1995), Artesanía tradicional atacameña en la Segunda Región (1996), Habitantes indígenas prehispanos del litoral del norte de Chile (1997), Colecciones artísticas arqueológicas del norte de Chile (1998), Doce milenios (1999). Una visión social de género de la historia del Norte Grande de Chile (1999), Arte textil prehispano del norte de Chile (1999), El poder en las comunidades prehispanas del norte de Chile (2000), Nuestraidentidad y patrimonio prehispano (2001), Arte prehispano del norte de Chile (2002), Vivir el mar (2003), Ciencia y tecnologías andinas (2009). A partir de 1999, edita los siguientes libros como parte de las muestras museográficas: Doce milenios. Una visión social de género de la Historia del Norte Grande de Chile (1999), El poder en las comunidades prehispanas del norte de Chile (2000), Nuestras identidades. Reflexiones. A propósito de la prehistoria de Tarapacá y Antofagasta (2001), Visión histórica del arte preinkaico (2002). Norte de Chile; Vivir el mar (2003), Vivir y morir en los Andes: reflexiones (2005), Tawantinsuyu y España: Dos tradiciones y el siglo XVI con tópicos de ciencia y tecnología (2009). En 1992 publicó "Chacance, los primeros pampinos" y luego de jubilarse, publicó como investigador adjunto del Museo Augusto Capdeville Rojas de Taltal: El Arte de Navegar y de la Construcción Naval (2015) y Vivir después de Soñar (2016).

Se suman a su importante trabajo de divulgación científica, los cursos de formación general ofrecidos a los estudiantes de diversas carreras universitarias: Cultura y Arte del Mundo Andino, Antropología e Historia del Feminismo en Chile y El Mundo Andino. Pasado, Presente y Futuro, que entregaba con sus originales y entretenidos enfoques críticos, integradores del pasado con la realidad actual.

Sea este recuerdo parte del reconocimiento a la obra de Patricio Núñez Henríquez, sumado a sus aportes en el ámbito de la arqueología y la antropología. Testimonio de su verdadero compromiso social y su dimensión de científico y educador generoso, máxime cuando sabemos que en la academia de los doctores la extensión no redituaba y la divulgación no daba prestigio.

Gracias amigo Pato, te extrañamos!

Gaiman, Argentina, mayo 2018

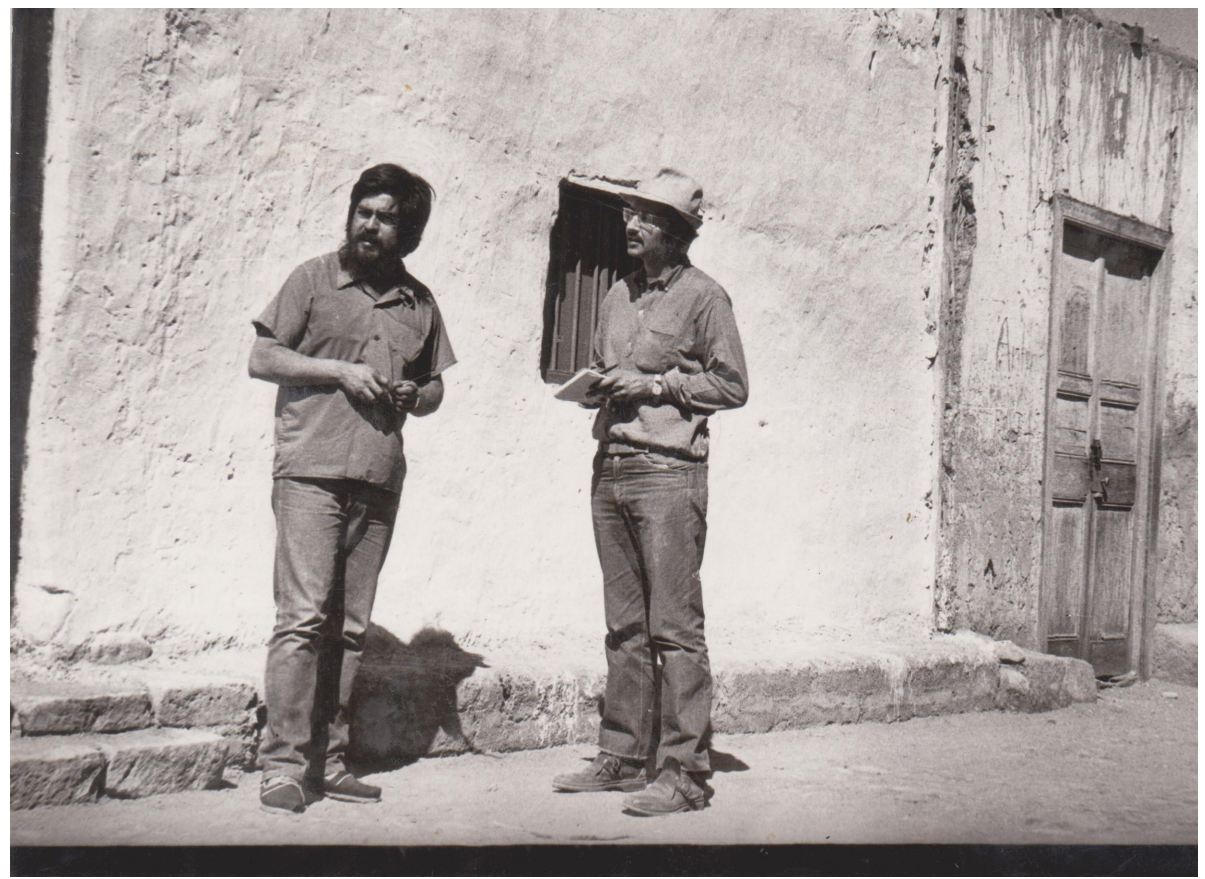

Patricio Núñez y Branko Marinov en el pueblo de San Lorenzo de Tarapacá, julio 1972 (fotografía cortesía de Branko Marinov). 


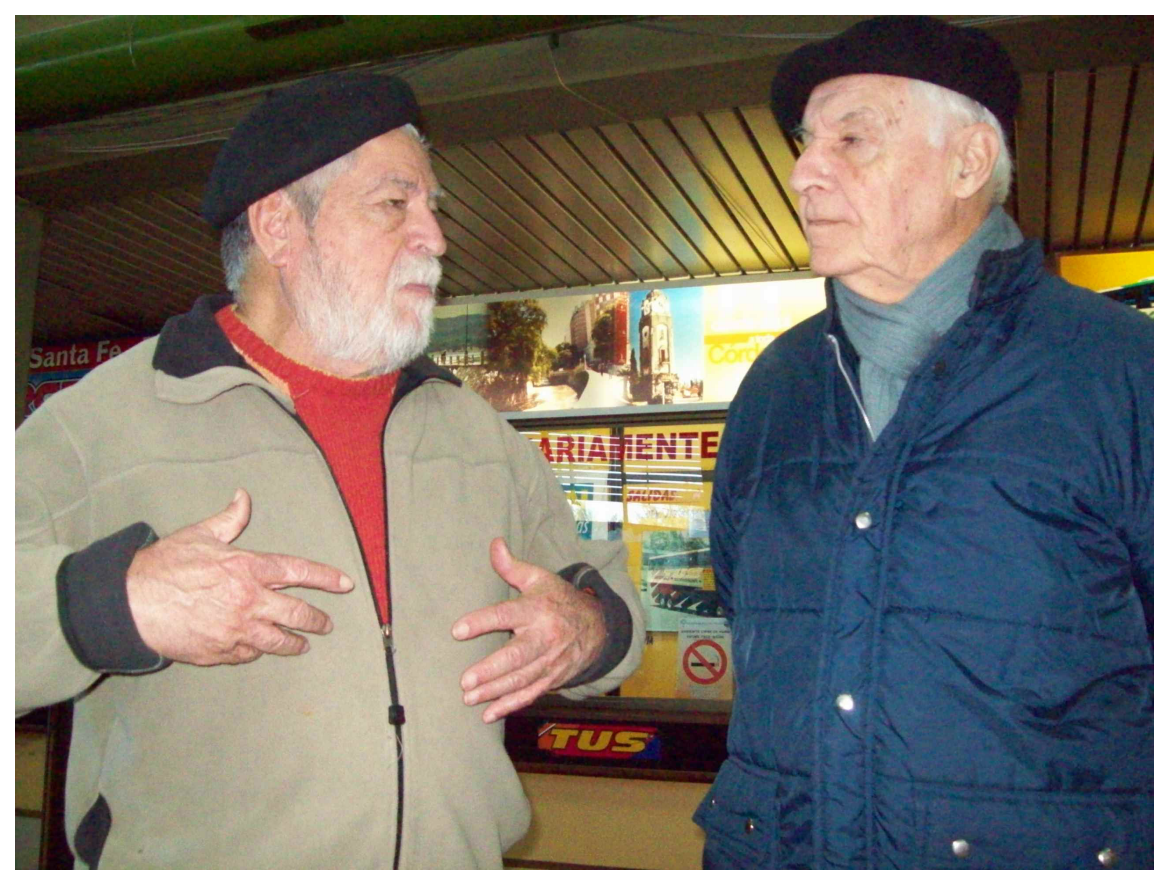

Patricio Núñez y Branko Marinov en Gaiman, Argentina, agosto 2013 (fotografía cortesía de Branko Marinov). 